Portland State University

PDXScholar

6-16-2021

\title{
The Meghan Markle Effect: An Analysis of a 21st Century Celebrity through a Veblenian Perspective
}

Lucy Jensen

Portland State University

Follow this and additional works at: https://pdxscholar.library.pdx.edu/honorstheses

Part of the Economics Commons

Let us know how access to this document benefits you.

\section{Recommended Citation}

Jensen, Lucy, "The Meghan Markle Effect: An Analysis of a 21st Century Celebrity through a Veblenian Perspective" (2021). University Honors Theses. Paper 1084.

https://doi.org/10.15760/honors.1111

This Thesis is brought to you for free and open access. It has been accepted for inclusion in University Honors Theses by an authorized administrator of PDXScholar. Please contact us if we can make this document more accessible: pdxscholar@pdx.edu. 
The Meghan Markle Effect:

An Analysis of a $21^{\text {st }}$ Century Celebrity

through a Veblenian Perspective

by

Lucy Jensen

An undergraduate honors thesis submitted in partial fulfillment of the requirements for the degree of

Bachelor of Science

in

University Honors

and

Economics

Thesis Advisor

John Hall

Portland State University 2021 


\begin{abstract}
:
Following her engagement and subsequent marriage to Prince Harry, Meghan Markle has emerged as a global figure and fashion icon. Her ability to influence fashion trends has been labelled the "Meghan effect" by the news media. This thesis research applies the theories of Thorstein Veblen, an economist and author of the extremely influential Theory of the Leisure Class (1899). The thesis has the aim of clarifying how Veblen's thinking can be applied to Markle or comparable high-profile women. What this inquiry ultimately finds is that Veblen was indeed correct in his assumption that high-profile, wealthy people such as Markle can influence consumer behavior. However, Veblen falls short is in his understanding of the importance of fashion: in that he lacks in understanding the function of fashion beyond aesthetic and pecuniary considerations. By using Markle as a prototype of the modern-day celebrity, this thesis aims to add to Veblen's theoretical legacy and update it for the $21^{\text {st }}$ century.
\end{abstract}

JEL Classification Codes: B15, B31, B54, L67

Keywords: Meghan Markle; Thorstein Veblen; Conspicuous Consumption; Fashion; Celebrity

Acknowledgements: I would like to thank John Hall for being a wonderful advisor throughout my writing process. I could not have completed this without his guidance. I would also like to thank my mother for giving me the idea to write about this topic. And while I am almost certain she will never see this, I would like to extend a thank you to Meghan Markle- I have the utmost admiration for you, your work, and your impact on the world. 


\section{Introduction:}

This inquiry seeks to establish that as a prominent figure and celebrity of sorts, Meghan, the Duchess of Sussex (referred to in the media as Meghan Markle) exerts effects over patterns of consumption. Certainly, Markle has registered as a prominent figure in the world over the last few years, at least since she stepped onto the world stage with the announcement of her engagement to Prince Harry, the grandson of the late Prince Philip and Queen Elizabeth II of England. Immediately following her foray into the public eye, Markle took on the mantel of a style icon. Her influence over tastes of consumers and those managing the fashion industry was deemed "the Meghan Effect," as the attire she wore often sold out within a day after an appearance. This Meghan Effect can be measure in the brands reporting vast increases in their sales. Some in the fashion industry even credit her with saving their businesses or making their brands prominent.

Generating such effects on consumption, and had they been contemporaries, Markle would likely have caught the eye of Thorstein Veblen, an American economist who was active with research and publishing about one hundred years ago. Veblen could be described as a 'cultural economist' who took an interest in stratification and groups in American society, in particular. In The Theory of the Leisure Class [1899] Veblen advanced the notion that the wealthiest individuals of American society could be grouped into what he refers to as leisure class, a community that he identifies as engaging in 'conspicuous consumption'. This suggests that members of this class purchase items in order to display that they have wealth.

Related to Markle's status as a prominent figure that could boast connections to the House of Windsor through marriage — as well as a fashion icon for many_ one could posit Markle would belong to what Veblen described as leisure class. However, what proves 
interesting and will be developed in this inquiry is that Markle is, in actuality, a working mother and a multitasker. Prior to her joining Britain's royal family through marriage, she was a selfmade working woman. Following her resignation as a senior member of the royal family, she has resumed a professional career through the creation of Archewell Productions.

With this Honor's Thesis I shall examine the extent to which Markle influences consumer behavior. This shall lead me to examine current theories of consumer behavior given the explosion of celebrity culture. Then I shall and compare what I have coined as the 'Meghan effect' to other members of Britain's Royal family. Undertaking this inquiry should, in my opinion, also help to restore an interest in Veblen's thinking though relating ideas he advanced more than one hundred years ago to developments taking place in the first decades of the twentyfirst century.

\section{The Theories of Thorstein Veblen}

\section{A. Veblen's Theory of the Leisure Class}

Thorstein Veblen was an American economist and writer. His text The Theory of the Leisure Class, published in 1899, registers as influential text because it is credited with the founding of the field of Evolutionary-Institutional Economics. In this text, Veblen argues that the economic structure of modern society is based upon a stratified society, meaning that people are categorized into groups based on wealth rather than merit.

Here, Veblen (1899) loops in history to make his arguments. He advances the idea that stratification could indeed be traced back to tribal societies in which division of labor amongst men and women would be dictated by one's social and economic standing. The wealthy and people of high status would engage in warfare and hunting, which Veblen deemed to be 
unnecessary. This stood in contrast to the work of lower-status individuals, engaged occupations that Veblen saw as productive and necessary to the functioning of society. This would include farming and artisanal activities.

After laying out historical context, Veblen presents his theory: he argues that the wealthy, or "leisure class" aims to achieve status. They will do this by purchasing material goods that project the image of wealth; Veblen $(1899,75)$ later coins the phrase "conspicuous consumption" According to Veblen $(1899,31)$, possessing property is the foundation in achieving a high standing. Therefore, members of the leisure class are less concerned with the comfort that these items bring than the status which they provide.

Throughout the text, Veblen goes further into detail about these ideas and provides specific examples of what he considers to be conspicuous consumption and leisure. Veblen $(1899,167)$ cites clothing as an example, as he believes that there is no quicker way to showcase one's socioeconomic standing than by how they dress. Veblen $(1899,168)$ argues that wealthy individuals wear clothing simply for the purpose of displaying wealth without concern for its utility. In fact, Veblen $(1899,170)$ states, members of the leisure class purchase clothing that lacks the utility that working class individuals may need to show that they do not engage in productive work. Furthermore, the wealthy can buy clothing when fashion trends change. Therefore, the cycle of conspicuous consumption never ends because there will always be new trends to take part in.

Veblen $(1899,212)$ then explains the concept of emulation. Veblen $(1899,212)$ states that the lifestyle of the wealthy will cause lower-status individuals to want to attain the status that wealthy individuals have; they will then take part in economic activities such as conspicuous consumption and adopt "archaic" attitudes that reflect the beliefs of the higher class. style. This 
was further explained by McCormick, whose text Veblen in Plain English (2006) breaks down how humans have both self-regarding and group-regarding instincts which are not independent of each other; at times they will be congruous and at times they will be contradictory (7). Due to the nature of society and institutions, humans are constantly comparing themselves to others and become status conscious. This will drive humans to emulate the wealthy to be seen as "better."

\section{B. Difference from other economic theories, namely that of mainstream} neoclassical economics.

During his lifetime, Veblen was noted as a staunch critic of $20^{\text {th }}$ century American capitalism and the rise of big business, and his views contrasted those of mainstream economics, known as neoclassical economics. Neoclassical economics has its roots in Jeremy Bentham, who wrote about "felcific calculus" that later would come to be integrated into William Jevons book The Theory of Political Economy [1871]. In this book W. Stanley Jevons roots consumption decisions in a consumer's assessment of 'utility' and 'marginal utility', laying the foundation for what later became established as the mainstream, Neoclassical Economics. As opposed to Veblenian theory, which emphasizes the role of society in one's behavior, neoclassical economics emphasizes personal choice. In the world of neoclassical economics, consumers are rational. This means that the consumer will make purchasing decisions based on her own preferences, choosing the alternative that will maximize utility. Furthermore, the prices of goods and services are completely based on the supply and demand model.

As one can see, this is highly different from the theories that Veblen has posited, as it emphasizes individual choice and rationality, while leaving out the role of society in a consumer's decision making. Veblen, on the other hand, argues that society and institutions play a significant role in consumer behavior. 


\section{Veblen's theories about women.}

One area that mainstream economics often overlooks, particularly prior to the twentieth century, was the role of women in the economy. In this respect, Veblen appears to be ahead of his time, as he wrote about women's status and economic contributions during his lifetime. Hall and de Souza Luz (2020) explore the way in which Veblen pioneered feminist economics. According to Hall and de Souza Luz $(2020,411)$, Veblen's beliefs were that the beginning of property has less to do with the seizure of goods and more to do with the seizure of persons, i.e., women. Veblen advances the notion that women were to be understood as the personal property of their husbands. These women were viewed as "chattel" and provided economic benefit through unpaid labor and offspring. Women were then responsible for communicating their husband's economic standing through their attire. Despite their economic contributions, they face subjugation due to the institutions that neoclassical economics fail to recognize.

Women have gained significant social standing in the decades since Veblen's lifetime, yet institutional sexism still exists in the United States. It is the subject of many works of literature including, as Hall and de Souza Luz $(2020,414)$ The Handmaid's Tale (1985) by Margaret Atwood. Hall and de Souza Luz $(2020,414)$ also cite the decades-long battle over Roe v. Wade, the landmark decision that ruled abortion constitutional. To this day, women are still subjected to legislation that attempts to control their bodies, in some ways validating Veblenian thinking on the male subjugation of women.

\section{Veblenian viewpoint of Meghan Markle}


The rise of celebrity culture can also be seen as supporting the ongoing relevance of Veblen's thinking. Celebrity culture has exploded in the twenty-first century, and many consumers are highly interested in the lives of the rich and famous, and have unprecedented access to details about their lives, including their fashion choices. This shows that Veblen was right in many respects; many consumers desire to emulate celebrities who are likely much wealthier than they are.

As this essay argues, Meghan Markle hardly complies with Veblen's definition of the leisure class. Yes, she is very wealthy compared to the general population; however, her lifestyle does not necessarily match up with what Veblen initially considered. Today, Markle would be considered a multitasker as well as a working mother. She can also be considered a normbreaker, given her decision to step back as a senior member of the royal family. This raises the idea that consumers are drawn to a different set of people than what Veblen had originally thought. As perspectives around working women have drastically changed since the turn of the twentieth century, one could argue that consumers are drawn to celebrities who are also working professionals and multitaskers like Markle. Overall, this will serve as a way to examine Veblen's theories and add to his legacy by bringing his ideas into the twenty-first century.

\section{Meghan Markle Bio}

\section{A. Life Prior to Prince Harry}

Meghan Markle is an American member of the British royal family, having joined the family after her marriage to Prince Harry (Biography.com editors, 2021). She is a biracial woman who was raised in Los Angeles, California. After graduating from Northwestern University with a degree in theatre and international relations, Markle pursued an acting career 
(Biography.com editors, 2021). Her first major role came when she was cast in the legal drama Suits, beginning in 2011. During this time, Duchess Markle married film producer Trevor Engelson. However, the two got divorced in 2013.

Meghan Markle was further known for her advocacy work, particularly within the realm of women's rights. Meghan Markle showed interest in feminism and politics at a young age; at the age of eleven she wrote letters to Proctor and Gamble and First Lady Hillary Clinton regarding a sexist advertisement she saw in her social studies class (Biography.com editors, 2021). She also expressed interest in pursuing a career in politics while she was in college, however she ultimately pursued her acting career.

As a working actress, Markle continued her advocacy work by partnering with organizations such as World Vision Canada, One Young World, and the United Nations (Holmes, 2020). In 2016, she endorsed Hillary Clinton for President of the United States, voicing opposition to many of the remarks that her opponent, Donald Trump, had made, stating that they were sexist (Booth 2017).

\section{B. Life dating, getting engaged to, marrying Prince Harry}

Meghan Markle began dating Prince Harry in July of 2016; the relationship was first publicly confirmed in October of that year, when the royal family's communications team released a statement condemning the "wave of hate and abuse" directed toward Markle (Biography.com editors, 2021). After over a year of dating, the couple announced their engagement in November 2017. With this announcement also came the announcement that Meghan would leave her TV show Suits. The Palace also announced Markle's intention to retire 
from acting, begin the process of becoming a British citizen, and convert to the Church of England (Biography.com editors, 2021).

Upon the announcement of Meghan and Harry's engagement, many media outlets noted the historical significance of Markle joining the royal family. Many noted that she would be the first mixed-race woman to join the royal family. Nevertheless, Meghan and Harry's engagement was noted as significant because of the monarchy's dearth of racial diversity, in contrast to the Commonwealth's high level of diversity. Media outlets also noted the fact that she was older than Prince Harry, she was an American, an actress, and a divorcee. Many also pointed out that she was an outspoken feminist and humanitarian; this was seen as significant because the royal family tends to stay quiet about political issues. Due to these qualities, many journalists commented that Markle would help usher in a new age to the royal family, one that would help bring the monarchy into the twenty-first century (Barry 2018).

Meghan Markle and Prince Harry married on May 19th, 2018, at Windsor Castle; the wedding was noted as significant by Barry (2018) not only due to the excitement around another royal wedding, but also because of its celebration of African American culture. In the months following their wedding, Markle and Prince Harry embarked on several royal tours. They visited many countries within the Commonwealth, including Ireland, New Zealand, Fiji, and Morocco (Holmes, 286). In late 2018, Meghan and Harry announced that they were expecting their first child. In May 2019, Meghan gave birth to their child, a boy, named Archie Harrison Mountbatten-Windsor (Barry 2019). Following the birth of Archie, the Duke and Duchess continued with their royal duties, embarking on tours throughout the Commonwealth and engaging in philanthropy efforts as members of the royal family. 


\section{Leaving the Royal Family}

On January 7th, 2020, Prince Harry and Meghan Markle announced that they were stepping back as senior members of the royal family and announced their intentions to split their time between England and North America (Biography.com editors, 2021). After living in Canada for a short period, they soon re-located to Southern California.

Deemed "Megxit" by the media, Meghan and Harry's announcement and subsequent departure from the United Kingdom was a major world event and was the subject of much media attention. Many news outlets outside of the United Kingdom, however, noted that this should come as no surprise to the general public. Journalists, particularly in the United States, noted the negative and racist news coverage from the British press (Landler 2020). Many also pointed to a 2019 clip of Meghan Markle, in which she stated how hard it was to adjust to the wave of negative press aimed at her. Some also suggested the idea that Markle's previous lifestyle as an actress and an activist might have been incompatible with her role as a member of the royal family due to the restrictions placed on its members.

A primetime interview with Oprah Winfrey shed further light on Meghan and Harry’s departure from their roles and their life since moving to Southern California (Lyell 2021). Much as the American news media suspected, negative and racist press coverage of Meghan played a role into why they decided it was necessary to leave; this was compounded with the fact that the royal family was unwilling to protect Meghan in the way that it protected other members of the royal family. According to Markle, racist behaviors were also exhibited by members of the royal family; one member of the royal family reportedly expressed concerns about what color Archie's skin would be. Markle also stated that the royal family refused to grant Archie a title, going against centuries of tradition, and that this would result in Archie not receiving any security. 
Additionally, Markle stated that "the firm" (the nickname for the business side of the royal family) refused to aid her when she came to them about feeling suicidal about the amount of racist press she was receiving from the British press. The interview also delved into their life since moving to Southern California; after being financially cut off from the royal family, Meghan and Harry brokered massive deals with Netflix and Spotify to produce content for their platforms.

In addition to becoming a public working figure, Meghan has also delved into the political sphere since moving to Southern California. This was extremely notable due to the requirement that the royal family stays neutral on political matters. Markle encouraged Americans to vote in the 2020 election; given her previously expressed political views, many considered this to be an endorsement of Joe Biden (Hubbard, 2020). In 2020, she became the first member of the royal family to vote in a United States election; she did not state who she voted for (Hubbard, 2020). She also expressed support for the Black Lives Matter movement following the murder of George Floyd, stating in June of 2020 that, "Black lives matter... George Floyd's life mattered, Breonna Taylor's life mattered, Philando Castile's life mattered, and Tamir Rice's life mattered" (Nicholl 2020).

In February 2021, Markle announced she was pregnant with her second child, later revealing to Oprah that it was a girl and would be arriving in the summer (Mzezewa 2021).

\section{The Meghan Effect}

Meghan Markle’s entrance onto the world stage as Prince Harry’s fiancé resulted in Markle being deemed an international style icon. Meghan's fashion is frequently monochromatic, and she has been noted as wearing classic styles with crisp and tailored pieces. Vogue contributor and royal expert Elizabeth Holmes notes in her text HRH: So Many Thoughts 
on Royal Style (2020) that her sense of dress has been relatively tailored and pared back However, she has been known to break some of the norms that are expected of the royal family. For example, she has worn black nail polish to events (the royal family's rule is to only wear nude or pale pink) and has worn trousers rather than dresses to several official events.

With her fashion icon status, Meghan seems to have a significant influence over the behavior of consumers. More specifically, the clothing that she wears often sells out immediately and brands report a huge spike in sales and website traffic. This is known as "the Meghan effect" and has been documented by the press at length.

The Meghan effect has been in full force since her engagement announcement to Prince Harry in 2017. At their engagement photocall, Markle wore a white knee-length robe-coat from Canadian brand Line the Label. Fashion journalists Katie O’Malley and Daisy Murray (2019) reported that this white coat sold out just minutes after the photographs went public, and traffic to their website to such a significant extent that it crashed for a period of time that day. The green dress that Markle wore to the photocall also sold out within the hour after photographs became public. Her engagement ring also felt the Meghan effect; her ring had a yellow gold stone, and the United States reported a significant increase in yellow gold jewelry. Jeweler David Borochov stated, "Yellow gold jewelry sales have risen about 30 percent this year." As a result, 2018 had the highest demand for yellow gold in nine years (Young, 2018).

Her engagement announcement was not the only time in which the Meghan effect occurred; this trend has continued in the years since becoming engaged to Harry. Many established, big-name clothing brands have felt the benefits of Markle wearing their clothing. Markle's influence, however, has not just been confined to big-name brands; she is also credited with putting smaller brands on the map and helping them to succeed. In addition to 
items that she wears selling out, she can influence larger patterns of dressing. For example, in September 2019, Markle donned several shirt dresses during her tour of South Africa with Prince Harry. O’Malley and Murray (2019) state that, in the following weeks, searches for shirt dresses increased by forty five percent.

Just how significant is the Meghan effect? The word 'huge' proves descriptive. In the leadup to her wedding in 2018, economists at Brand Finance (2018) estimated that she would infuse 150 million euros into the British economy which would stem from consumers attempting to emulate her fashion. Brand Finance economists (2018) also stated that Markle, along with Prince Harry, would infuse over one billion dollars to the UK economy. At the end of 2018, Women's Wear Daily (2018) estimated that Markle's clothing was worth over 200 million dollars when adding up total sales as well as impressions online and on social media. Furthermore, fashion website Lyst named Meghan Markle England's most powerful dresser due to the fact that Markle caused a 216 percent average increase in web traffic relating to the clothing she wore (O’Malley and Murray, 2019).

It is also important to take into consideration sustainability and sustainable fashion, which Markle has been known to wear on numerous occasions. She has been referred to as an “ethical tastemaker” by journalist Grace Cook (2020) at fashion magazine Grazia Daily. O’Malley and Murray (2018) state that her wearing of sustainable fashion has had wide-ranging impacts on these brands' sales. Her tendency of wearing sustainable fashion has been stated to have effects on how consumers view sustainable fashion; O’Malley and Murray (2018) state that sustainable fashion did not necessarily have a great reputation before Markle came onto the scene. Alexandria Spring (2018) states that Meghan's embracing of the sustainable fashion 
industry could lead to sustainable fashion becoming increasingly mainstream rather than a niche trend.

Cuomo (2019) finds that celebrity endorsements of sustainable fashion play a key role in whether consumers will buy sustainable clothing. These effects are certainly present for Markle; sustainable fashion brands have seen their web traffic increase as much as 3000 percent after Markle has worn their clothing (Storey 2018). Furthermore, sustainable fashion brands such as Harriet and Outland Denim have been able to hire dozens of new employees thanks to Markle.

Royal expert Elizabeth Holmes $(2020,254)$ states Markle's fashion is relatable and accessible to the masses due to its relative affordability and accessibility; it is quite easy to emulate her style. Because of this, many brands have tried to cash in on the Meghan effect by creating copycat designs for considerably less money. For instance, Markle's Stella McCartneydesigned wedding reception dress led to, as Alisa Wolfson (2018) put it, "a...race to be the first [designer] with a replica." Over a dozen copycat designs were created in the weeks following their wedding, some of which were as low as 22 dollars (Wolfson 2018). Furthermore, many social media pages are solely dedicated to her fashion and providing users with considerably less expensive alternatives. Many of these accounts and websites have tens of thousands of active users. While I was not able to calculate the exact correlation between the two, one may infer that following Markle fan pages dedicated to fashion indicates an interest in her style.

Upon the announcement of Markle exiting as a senior member of the royal family, journalist Elizabeth Paton (2020) at the New York Times posited that this could lead to the United Kingdom losing billions of dollars, as many United Kingdom brands have benefitted from her endorsement of their products as well as her likeness to sell merchandise including coins and dish towels. 
Despite arguments within the fashion community that the Meghan effect may be waning, there is evidence to support the claim that it is still going strong. For example, a blazer she wore in March 2020 sold out, and searches for similar blazers increased by 92 percent the following day (Street 2020). One must also consider that, since stepping back as a senior royal, Markle has made considerably fewer public appearances.

Markle and Prince Harry's primetime interview with Oprah seemed to be a testament to Markle's power. According to preliminary Nielsen figures, over seventeen million viewers tuned in as it was airing. Koblin (2021) stated this was a significant number of people given the rise of streaming services and a lesser emphasis on appointment television. The aftermath of the interview also seemed to indicate that the Meghan effect still had considerable power; the chairs that Markle and Harry sat in had sold out by the next day (Ritschel, 2021). Additionally, Markle's mention of the location of her first job, a frozen yogurt shop named Humphrey Yogart, caused a spike in sales at the shop. According to its owners, the business served 200 people per day following the interview, up from a daily average of about 50 (Salaky and Morillo, 2020).

Additionally, major companies still seem to have confidence in Markle's ability to influence consumer behavior. Harry and Meghan signed megawatt deals with both Netflix and Spotify, two of the biggest streaming companies that exist. While much of their content has yet to be released, this shows a significant amount of confidence in Markle and Prince Harry's ability to pull in consumers. Furthermore, the effects of Meghan Markle's actions shows that her ability to influence is not limited to the realm of fashion. It extends into business, politics, and activism.

\section{Meghan Markle and Social Media}




\section{A. Recent studies on celebrities' social media \& their effects on consumer behavior}

Many studies have been written in recent years about what drives consumer behavior. Much of it seems to fall in line with Veblenian thinking. The role of the celebrity endorsement has changed in the twenty-first century due to the rise of social media. Additionally, fashion has continued to evolve and consumers' attitude towards fashion has evolved, requiring a reexamination of Veblenian theory.

Celebrity endorsements have existed for many years in the United States. Celebrity endorsements can be traced back to the 1890s. Cuomo et al $(2019,2)$ cites the year 1896 as the earliest example. Throughout the following decades, celebrity endorsements became increasingly popular. According to Cuomo et al, $(2019,2)$ use of celebrity endorsements in television commercials had risen to over fifteen percent by the 1960s. Today, it hovers around 25 percent in the United States and the United Kingdom. This article further states that "of the billions of dollars allocated annually for television advertising, approximately $10 \%$ is served on endorsers" $(2019,2)$.

Why is celebrity endorsement useful in marketing? Cuomo et al states $(2019,2)$, that they can cut through the clutter, offering the brand an increased reputation of glamour, particularly if the celebrity's values are perceived to be congruent with the brands they are endorsing.

\section{B. Examination of Instagram accounts dedicated to Meghan's attire.}

Meghan Markle herself is no longer on social media, yet many fan accounts exist; these accounts essentially act as fan pages that post photos of Markle and any new updates in her life. Many of these accounts are extremely popular; it is not uncommon to find a fan page with tens or 
even hundreds of thousands of followers. Some of these accounts are dedicated exclusively to her fashion choices; these accounts are also quite popular. For example, Dress Like a Duchess is an account focused on the fashion choices of Kate and Meghan and provides links to affordable fashion inspired by their clothing (dresslikeaduchess, 2021). As of April 26th, this account has 162 thousand followers. Another popular Instagram account is Meghan's Closet Chronicles, which boasts almost thirty thousand followers (meghansclosetchronicles, 2021). Similarly to Dress Like a Duchess, this account is dedicated to showcasing Meghan's fashion choices and provides links to outfits that are similar to Markle's at a more affordable price.

I was not able to conduct an analysis of what percentage of followers are able to go out and buy clothing inspired by Meghan Markle. The existence of these accounts and the number of followers they possess shows a wide interest. Comments show an admiration for Markle. Many users remark on her physical appearance, commenting things such as "she doesn't age" and "she is a natural beauty" (meghansclosetchronicles, 2021).

The connection between physical appearance and Markle's appeal as a fashion icon is shown to have something of a positive correlation with recent studies about what drives consumer behavior in the digital age. A recent study about consumer behavior by Newbert (2020) amongst millennials and Gen-Z'ers found that physical appearance of the endorser was one of the most important factors in choosing whether to purchase similar products (22). Related to the frequent comments made about Markle's physical beauty, one may posit that her beauty plays an important role in her influence.

Newbert's (2020) paper about consumer behavior finds that millennials and Gen Z-ers are highly influenced by celebrity fashion. Analysis of this article may show that Meghan Markle fulfills many of the categories by which consumers are influenced. According to 
Newbert $(2020,27)$, one of the strongest motivators for consumers is a sense of celebrity-brand congruence. Newbert $(2020,27)$ states celebrity-brand congruence is achieved when "there is a clear meaning as to why he or she is endorsing the brand or product." Given Meghan Markle's tendency to speak out about political and social issues, it may be that her wearing of sustainable fashion matches with her public persona.

\section{Examination of social media comments made about Meghan Markle.}

Given Meghan Markle's status as a member of one of the most famous families in the world, she is a frequent subject of discourse on social media. This was particularly intense in the months leading up to her wedding to Prince Harry. Comments posted on Facebook were analyzed by Mahfouz (2018) that offered a subset of the discourse surrounding Markle.

First and foremost, it is impossible to discuss press coverage of Markle without acknowledging the amount of negative and racist press coverage that she has received. Mahfouz $(2018,253)$ noted that, upon her engagement announcement, many individuals commented that she is a "disgrace" to the royal family; one commentor wrote that Markle was a "Hollywood hog that snagged the ring."

Upon Markle's departure from her role as senior royal, Ellie Hall (2020) at Buzzfeed News published an article that compared 20 headlines from the British tabloids that compared Meghan Markle and Kate Middleton for doing the same thing. For example, when Middleton was pregnant with Prince Louis, the Daily Mail published an article titled, “...Kate Middleton

tenderly cradles her baby bump..." On the other hand, when Markle was pregnant with Archie, the Daily Mail ran a story titled "Why can’t Meghan Markle keep her hands off her baby bump?... Is it pride, vanity, acting, or a new age birthing technique?" 
Mahfouz $(2018,253)$ also found that the more positive or even neutral coverage of Markle seemed to emphasize the fact that Markle was a normal woman (compared to other royal spouses), an American, black/mixed-race, modern, outspoken feminist. Frequent comments made about Markle in this respect include "she inspires me in so many ways," "broke every tradition of the British Royal Family," and "vocal on issues of race and gender equality"

When examining the positive press coverage of Markle, much of it seems to fall in line with the theories in part A about what drives consumer behavior. Particularly that of her appearance; many find her to have a natural beauty and elegance. According to Mahfouz (2018, 256), common words used to describe Markle were" stylish, gorgeous, beautiful, pretty, lovely, feminine." Her wedding dress was described by one particular user as "glamorous." A subset of the population saw Markle as "a breath of fresh air" compared to the other members of the royal family (who are almost exclusively white, royal, or who come from backgrounds of inherited wealth). Comments about her beauty seem to fall in line with theories of consumer behavior.

An examination of the negative treatment of Markle suggests that Veblenian theory is present in some respects. While Veblen did not write explicitly about race, his writings about gender and class shows that he possesses an understanding of the role of institutions and inequalities. If he were to examine the racism that has been hurled at Markle, he likely would have expressed those institutions attempted to subjugate her. This is particularly clear when one examines Kate Middleton, Markle's sister-in-law and the wife of Prince William. As a white woman who plays a somewhat traditional role within the royal family, the press treats her in a much kinder fashion.

\section{Comparison to other high-profile individuals}


When analyzing the press coverage and social media comments made about Markle, Mahfouz $(2018,256)$ found that Markle was compared favorably to a few high-profile individuals.

Mahfouz $(2018,256)$ noted that, in the months leading up to Meghan and Harry's wedding, Markle was compared often to former United States President Barack Obama. Mahfouz $(2018,256)$ stated that people noted that as he was the first black president of the US, Markle would be the first black princess in the British royal family. Many also noted comparisons to the amount of racism and vitriol that the two individuals had received. She was also compared to Princess Diana, the mother of Prince Harry. Similarly to Diana, Meghan Markle has shown a great interest in humanitarianism and advocacy; She was also compared to Kate Middleton due to her status as a fashion icon; Mahfouz $(2018,256)$ acknowledged Middleton was also known to exert fashion influence over consumers.

The figures which she was commonly opposed to were Donald Trump and the Kardashians (Mahfouz, 2018, 256). Trump and the Kardashians are perhaps the best examples of a modern day Veblenian type given their effects on the culture and their public perceptions. The Kardashians, a family of reality television stars, are perceived by many as "famous for being famous." They could be perceived as a modern example of the leisure class, as they often embark on expensive vacations around the world and wear flashy clothing. The Kardashians have hugely impacted fashion, perhaps proving Veblenian theory of conspicuous consumption. Mahfouz $(2018,255)$ states that many Facebook commenters expressed the idea that Markle exemplifies simplicity and grace, whereas the Kardashians exemplify "vulgarity and artificiality." 
Donald Trump was also cited by Mahfouz $(2018,255)$ as a figure with whom people contrasted Markle. Comments contrasting Markle and Trump include: "She brings some dignity back to the USA that Cheeto has stripped us of." Trump seems to be a prime example of Veblen's theories, as he was often seen to be acting within his own self-interest. Even as President of the United States, Trump constantly bragged about his personal wealth, avoided paying taxes, and went on golfing excursions dozens of times throughout his presidency.

Taking a step back, one can acknowledge that these individuals have had enormous impacts on the culture and consumer behavior, showing that in this respect Veblen's thoughts still hold up over 120 years after the book's publication. However, positive comments made about Markle may be a factor for which Veblen could not have accounted.

\section{Comparison to Other Royal Figures}

\section{A. Royal family's history of influencing fashion trends}

Long before the internet and social media allowed consumers to access fashion on an immediate basis, the royal family has had a history of influencing fashion and being considered style icons.

According to Lindsey Baker (2018) at BBC Culture, a style icon dating back to the 1860s was Queen Alexandra, a woman who was originally a member of the Danish royal family, but later married Queen Victoria's son Albert Edward. According to Baker, "It seems Alexandra was just the kind of royal woman the public were craving" (2018). The article cites fashion curator Elly Summers, who states: "Queen Victoria had been in mourning dress for years and was quite removed from British society," explains Summers, "She wore a black austere uniform, and she didn't attend parties. Edward and Alexandra on the other hand were a dazzling couple who had 
an active social life and were seen as more accessible." This, according to Summers and Baker (2018) to them becoming style icons. Alexandra is credited with popularizing the trend of British women wearing tailored looks for daytime.

Baker (2018) acknowledges that Elizabeth II, the current queen of England, is considered a fashion icon, but focuses on her late sister Margaret; the press referred to her sense of style as “the Margaret look." Her style was considered to be bold and daring in comparison to her sister. Baker notes that, while the Queen favors timeless, brightly colored dresses, Margaret favored fashion-forward silhouettes, particularly the fit-and-flare dress that defined the 1950s. Her tendency to break away from tradition and embrace current trends earned her the nickname "royal rebel." Baker (2018) states that Margaret was also a norm-breaker of sorts; she was the first royal to divorce in over four hundred years

Princess Diana, the mother of Prince Harry, was also an international style icon. According to royal expert Elizabeth Holmes $(2020,87)$, Diana understood the power of fashion. Diana knew how to create headlines with the clothes she wore, and she was known to break fashion norms. Diana was known for blending menswear and womenswear, often mixing elegant silhouettes with more tailored pieces. According to Holmes (2020), Diana was also known for being bold in her clothing choices, often wearing a variety of bright colors to provide comfort to children she visited.

According to Holmes (2020), it was uncommon for designers to receive credit when a royal wore one of their pieces during Diana's lifetime. However, on the few occasions in which this happened, designers received an increase in sales. For example, after designer Amanda Wakely was cited as the designer behind a green skirt suit worn by Diana, "it was all over every paper” and Wakely's other suits “sold out overnight” (Holmes 2020). 
Holmes $(2020,99)$ notes that Diana's fashion continues to be relevant today; many designers credit her style as inspiration for their collections. Some of these designers include Tory Burch and Virgil Abloh, both of whom cited Diana's fashion and spirit to influence their recent fashion collections. In a recent issue of French Vogue, model Hailey Bieber recreated some of Diana's most iconic street style looks. Holmes $(2020,99)$ notes that this reveals lasting desire amongst the style-conscious world to emulate the style of Princess Diana, even decades after her death.

\section{B. Kate Middleton Analysis}

Before there was the Meghan effect, there was the 'Kate effect'. She has been credited with boosting sales in the UK. Time Magazine named her one of the 100 most influential people in the world, stating that Kate has "boosted the British economy" by a significant margin through people wanting to emulate her fashion (Smith, 2013). In 2018, Brand Finance found that Kate was "the most powerful royal fashion dresser," and found that her clothing pieces increased desirability among almost 40 percent of American consumers.

Some have noted that Middleton may have also been influenced by Markle's fashion. Middleton's fashion was known to be traditional and safe since her engagement to Prince William. However, royal expert Elizabeth Holmes (2020, 165) noted that Kate's style got considerably more daring in 2018, not long after Meghan Markle came into the family. Royal expert Elizabeth Holmes noted that Kate's wardrobe upgrade could perhaps stem from a desire to emulate Meghan's boldness.

\section{Implications}


The trend of royal women as trendsetters seems to vindicate the Veblenian theory, as there is perhaps no better example of the leisure class than the British royal family. Despite the notion amongst many that the institution is outdated, there remains a fascination with the royal family amongst the public and the media. Meghan Markle herself did not become an international style icon until her engagement to Prince Harry. However, Veblen failed to understand the true power of fashion, as the next section will explore.

\section{Fashion in the twenty-first century \\ A. Veblenian theory of dress}

Veblen wrote extensively about the function of clothing amongst the leisure class in The Theory of the Leisure Class as well as his text The Economic Theory of Women's Dress (1894) Veblen $(1894,198)$ states that fashion may have once been used as primarily an aesthetic expression. Veblen $(1894,204)$ goes on to argue that the role of dressing has shifted, however, and the leisure class now dresses with other factors in consideration. The first category is expensiveness: members of the leisure class wear articles of clothing that are clearly exorbitant in price. The second category is novelty: given that fashion trends change rapidly, the leisure class must always wear new clothing and must never wear the same thing twice. Veblen notes that heirlooms are an exception to this rule, as they showcase generational wealth and waste. The final category is ineptitude; while members of the lower classes must wear functional clothing, women of the leisure class must wear impractical clothing such as skirts and dresses to show that they spent most of their time engaging in leisure activities.

There are plenty of examples in the decades following Veblen's writings that vindicate these principles. Television shows such as the Lifestyles of the Rich and Famous focus solely on 
the extravagant lives of people with extraordinary wealth (Collins, 1990). Other television shows that dealt with these matters were Keeping up with the Kardashians and Gossip Girl; these shows showcased wealth and fashion in similar ways as the Lifestyles of the Rich and Famous.

There are also examples outside the world of television. During red carpet events, female celebrities often wear expensive and elaborate dresses; journalists then write "best-dressed" and “worst-dressed" lists that millions of people can access. Even celebrities' day to day outfits are often quite expensive, yet there still exists the desire from the public to wear clothing that is influenced by celebrities.

Finally, there exists a phenomenon known as the Veblen good: a product whose demand increases when its price increases, a contradiction of the law of demand (Finkle 2020).

Examples of Veblen goods include sports cars, diamond jewelry, and expensive artwork. These items showcase an individual's status above all else, as many of these goods to do not possess a significant amount of additional utility. These television shows and real-world examples show that Veblenian theory still applies in some capacity in the $21^{\text {st }}$ century.

\section{B. Counterargument}

Veblen seems to fall short in his understanding of the functionality of fashion beyond an aesthetic or monetary purpose. He seems to be neglecting the idea that fashion has always been an important tool to demonstrate the times in which we live or send political and activist messages.

Many high-profile women, including Michelle Obama, Congresswoman Alexandria Ocasio-Cortez, and Meghan Markle possess an understand that people are paying attention to what they are wearing. All of them have exhibited an awareness that people are paying attention 
to what they are wearing and have made efforts to send messages through their clothing that go beyond wealth and leisure. For example, Michelle Obama stated in her documentary Becoming (2020) that she used fashion to "embrace youth and diversity" (1:01:15).

Congresswoman Alexandria Ocasio-Cortez also serves as a high-profile fashion icon. As a female with working-class roots, she does not necessarily match Veblen's description of the leisure class; nevertheless, she has been elevated to serve as a high-profile individual and icon in her own right. Darcy Schild (2020) notes that Ocasio-Cortez seems to approach her wardrobe with similar intentionality as other high-profile individuals. At her swearing-in ceremony in 2019 she wore white to pay homage to suffragettes, as well as bright red lipstick to pay tribute to Supreme Court Justice Sonia Sotomayor, who wore bright red nail polish at her swearing-in ceremony. Congresswoman Ocasio-Cortez also wore white to the State of the Union Address in 2019. Ocasio-Cortez seems to have similar effects to Meghan Markle; Time magazine journalist Ellie Alter (2019) reported that, upon announcing her signature lipstick, the lipstick quickly sold out. Additionally, after being photographed sporting a bag from the brand Telfar, the brand reported an increase in sales by 162 percent (Cartner-Morley, 2021).

Referring to Meghan Markle, her clothing tends to have meaning ascribed to it beyond wealth. For example, in her primetime interview with Oprah, Markle wore a black dress with a white lotus flower; Landler (2021) stated that Markle's staff said this "symbolized revival and the will to live."

Therefore, there is a counterargument to be made that high-profile individual are not wearing expensive fashion for the sake of wearing expensive fashion. Furthermore, Meghan Markle's fashion is often described as "timeless" (O'Malley and Murray, 2019), negating the 
idea of novelty that Veblen present. To only see fashion in a consumerist and aesthetic viewpoint disregards the historic role of fashion and how it has reflected the times in which we live.

\section{Meghan Markle and Sustainability}

A deeper analysis of Markle's wardrobe and her effects on consumer behavior reveals that her fashion negates all three of Veblen's theories of dress. Firstly, she has many clothing pieces that are somewhat affordable; the more expensive pieces tend to have affordable knockoffs, negating the theory of expensiveness. Secondly, her wardrobe is highly functional, negating the theory of ineptitude. Finally, she negates the concept of novelty because she often re-wears articles of clothing multiple times. Her negation of novelty is further exemplified by her wearing of sustainable fashion. Brismar (2014) defines sustainable clothing as "manufactured, marketed and used in the most sustainable manner possible, taking into account both environmental and socioeconomic aspects" ensuring efficient and careful use of natural resources (water, energy, land, soil, animals, plants, biodiversity, ecosystems, etc.); (b) selecting renewable energy sources (wind, solar, etc) at every stage, and (c) maximizing repair, remake, reuse, and recycling of the product and its components." This stands in contrast to fast fashion, which emphasizes the quick and ever-evolving production of clothing, which has come under fire in recent years for harsh working conditions and being environmentally destructive. The website Edology (n.d.) notes that turnover for fast fashion design is extremely quick and high-volume; Zara, for example, produces over eighteen thousand designs per year with new designs coming in every three weeks. While fast fashion is often more affordable than luxury sustainable fashion, it adheres to Veblen's theory of novelty due to the high turnover rate. Sustainable fashion, on the other hand, 
negates this concept. All in all, it remains clear that Markle uses fashion as a form of social commentary that goes beyond aesthetics and wealth.

\section{Conclusion}

This inquiry has sought to establish that as a prominent figure and celebrity of sorts, Meghan Markle exerts effects over patterns of consumption. Many of the findings surrounding the Meghan effect have confirmed that she has a noticeable impact on the fashion industry. When examining Markle through the lens of Veblenian theory, it is clear that some of Veblen's ideas remain insightful, while others do not. Ideas that hold up include society's fascination with the lifestyles of the rich and famous. Celebrity culture and consumerism are just as prominent as ever, and consumers are influenced by celebrity fashion.

Veblen's notion of the "leisure class" might be outdated in the 21 st century. A woman such as Markle is a working mother and norm-breaker who strives to engage in meaningful work. Furthermore, the notion that fashion is merely meant for an aesthetic or consumerist purpose does not hold up either; many highly educated and prominent women, including Markle, seem to use fashion as a means for social activism. According to many fashion researchers, this has long been the case and is in no way a new phenomenon.

Overall, this offers a starting point for further research of Meghan Markle's fashion. While there are many research papers focused on consumer behavior and many articles focused on the Meghan Markle effect, these two characteristics are rarely compared beyond a quick discussion rather than an inquiry that delves deeper into her effects. Given Markle's relative 
recency with respect to world prominence, it remains to be seen what Markle's overall impact will be. Markle, however, needs to be appreciated as a deserving example of a larger trend. That is of high-profile women influencing fashion in ways which probably would have interested Thorstein Veblen, but which he failed to foresee.

\section{References}

Alter, C. (2019, March 21). Inside Rep. Alexandria Ocasio-Cortez's unlikely rise. Retrieved from Time.

Baker, L. (2018, April 24). How royal women have shaped fashion. Retrieved from BBC.

Barry, E. (2018, May 19). As Prince Harry and Meghan Markle Wed, a new era Dawns. Retrieved from The New York Times.

Barry, E. (2019, May 08). Harry and Meghan name Their Son: Archie Harrison MountbattenWindsor. Retrieved from The New York Times.

Biography.com editors. (2021, March 08). Meghan Markle. Retrieved from https://www.biography.com/royalty/meghan-markle

Booth, R. (2017, November 30). Meghan Markle's activism to be held in check by royal protocol. Retrieved from The Guardian

Brand Finance. Royal wedding to Boost British economy by $£ 1$ Billion: Press release. (2021, February 15). Retrieved May 21, 2021.

Brismar, A. (2014) "What is Sustainable Fashion?” Accessed at: https://www.greenstrategy.se/sustainable-fashion/what-is-sustainable-fashion/ . 
Cartner-Morley, J. (2021, February 12). How Kamala Harris made wearing pearls cool. Retrieved from The Guardian.

Collins, G. (1990, December 02). Now, a look at the life style of Robin Leach. Retrieved from The New York Times

Cook, G. (2020, April 24). Is Meghan Markle actually the ultimate Sustainable Influencer? Retrieved from Grazia Daily

Cuomo, M. T., Foroudi, P., Tortora, D., Hussain, S., \& Melewar, T. C. (2019). Celebrity endorsement and the attitude towards luxury brands for sustainable consumption. Sustainability, 11(23), 6791

dresslikeaduchess. (2021, April 1). Rules for royal dressing... [Instagram post]. Retrieved from https://www.instagram.com/p/CNIGP1Rn3aU/

Finkle, C. (2020, May 25). What is a Veblen Good? Retrieved from https://brandmarketingblog.com/articles/branding-definitions/veblen-good/

Hall, E. (2020, January 13). Here are 20 headlines Comparing Meghan Markle To Kate Middleton that might show why she and Prince Harry are cutting off royal reporters. Retrieved from Buzzfeed News.

Hall, J. B., \& de Souza Luz, M. R. (2020). Thorstein Veblen as Evolutionary Feminist Economist of the Progressive Era. Journal of Economic Issues, 54(2), 413-419.

Hallgren, N. (Director). (2020). Becoming. Higher Ground Productions.

Holmes, E. (2020). HRH: So many thoughts on royal style. New York, NY: Celadon Books.

Hubbard, L. (2020, November 03). Meghan Markle is voting in Today's presidential election. Retrieved from Town and Country Magazine

Jevons, William Stanley. The Theory of Political Economy (London: Macmillan, 1888) 3rd ed. 
Koblin, J. (2021, March 08). Oprah, Meghan and Harry draw 17.1 million viewers to CBS. Retrieved from The New York Times

Landler, M. (2020, January 08). Prince Harry and Meghan to 'step back' from royal duties in extraordinary retreat. Retrieved from The New York times

Landler, M. (2021, March 08). 'I just didn't want to be alive anymore': Meghan says life as Royal made her suicidal. Retrieved from The New York Times

McCormick, Ken. Veblen in Plain English. Youngtown, New York, N.Y.:\Cambria Press, 2006 meghansclosetchronicles. (2021, April 24). Meghan for Good Housekeeping... [Instagram post]. Retrieved from https://www.instagram.com/p/COESSKUn-8g/

Mzezewa, T. (2021, March 08). It's a GIRL: Meghan and Harry reveal that Archie will have a sister. Retrieved from The New York Times.

Newbert, J.(2020). Celebrity Impact on Fashion Brand Choice Using Social Media. (Master's thesis). Retrieved from https://scholarcommons.sc.edu/etd/6082

Nicholl, K. (2020, June 4). "Like hearing the Old Meghan": How Meghan Markle decided to finally speak out About George Floyd. Retrieved from Vanity Fair

O'Malley, K.; Murray, D. (2020, June 12). The Meghan Markle Effect: Has she really changed the fashion industry? Retrieved from Elle.

Paton, E. (2020, January 09). Losing Meghan, Prince Harry and (Potentially) billions of pounds. Retrieved from The New York Times.

Ritschell, C. (2021, March 11). Patio chairs used in Oprah interview with Harry and Meghan sell out online. Retrieved from The Independent

Salaky, K., \& Morillo, A. (2021, May 01). Sales at the frozen yogurt shop Where Meghan MARKLE worked have gone up since she mentioned it. Retrieved May 21, 2021, from 
https://www.delish.com/food-news/a35766640/meghan-markle-humphrey-yogart-yogurtshop/

Schild, D. (2020, December 22). Alexandria Ocasio-Cortez is changing the dress code of politics. Retrieved from Insider.

Smith, S. (2013, April 18). The 2013 Time 100: Kate Middleton. Retrieved from Time

Storey, K. (2018, November 8). Will Meghan Markle's Sustainable Fashion Make an Impact? Elle.

Street, C. (2020, March 12). Kate officially overtakes Meghan As 2020's biggest fashion influencer. Retrieved from https://www.standard.co.uk/insider/fashion/kate-middletonmeghan-markle-duchess-sussex-cambridge-fashion-influencer-a4384916.html

Veblen, Thorstein. The Theory of the Leisure Class. New York: Viking Press, 1967.

Veblen, T. (Nov 1984). The Economic Theory of Women's Dress. The Popular Science Monthly, 198-205.

Young, R. (2018, May 25). Meghan Markle makes gold sales Sparkle. Retrieved from Reuters 